\title{
The prevalence of clinically-relevant comorbid conditions in patients with physician-diagnosed COPD: a cross-sectional study using data from NHANES 1999-2008
}

Kerry Schnell ${ }^{1 *}$, Carlos O Weiss ${ }^{1}$, Todd Lee ${ }^{2}$, Jerry A Krishnan ${ }^{3}$, Bruce Leff ${ }^{1}$, Jennifer L Wolff ${ }^{1}$ and Cynthia Boyd ${ }^{1}$

\begin{abstract}
Background: Treatment of chronic diseases such as chronic obstructive pulmonary disease (COPD) is complicated by the presence of comorbidities. The objective of this analysis was to estimate the prevalence of comorbidity in COPD using nationally-representative data.

Methods: This study draws from a multi-year analytic sample of 14,828 subjects aged 45+, including 995 with COPD, from the National Health and Nutrition Examination Survey (NHANES), 1999-2008. COPD was defined by self-reported physician diagnosis of chronic bronchitis or emphysema; patients who reported a diagnosis of asthma were excluded. Using population weights, we estimated the age-and-gender-stratified prevalence of 22 comorbid conditions that may influence COPD and its treatment.

Results: Subjects 45+ with physician-diagnosed COPD were more likely than subjects without physician-diagnosed COPD to have coexisting arthritis ( $54.6 \%$ vs. $36.9 \%)$, depression (20.6\% vs. $12.5 \%)$, osteoporosis (16.9\% vs. 8.5\%), cancer ( $16.5 \%$ vs. $9.9 \%)$, coronary heart disease (12.7\% vs. $6.1 \%)$, congestive heart failure ( $12.1 \%$ vs. $3.9 \%)$, and stroke (8.9\% vs. $4.6 \%$ ). Subjects with COPD were also more likely to report mobility difficulty (55.6\% vs. $32.5 \%)$, use of $>4$ prescription medications ( $51.8 \%$ vs. 32.1$)$, dizziness/balance problems ( $41.1 \%$ vs. $23.8 \%)$, urinary incontinence (34.9\% vs. $27.3 \%)$, memory problems (18.5\% vs. $8.8 \%)$, low glomerular filtration rate (16.2\% vs. $10.5 \%)$, and visual impairment (14.0\% vs. 9.6\%). All reported comparisons have $p<0.05$.

Conclusions: Our study indicates that COPD management may need to take into account a complex spectrum of comorbidities. This work identifies which conditions are most common in a nationally-representative set of COPD patients (physician-diagnosed), a necessary step for setting research priorities and developing clinical practice guidelines that address COPD within the context of comorbidity.
\end{abstract}

\section{Background}

Chronic Obstructive Pulmonary Disease (COPD) is the $4^{\text {th }}$ most common cause of death in the United States, with projections that it will move into $3^{\text {rd }}$ place by 2020. Currently, COPD is the attributable cause of death for more than 120,000 deaths per year. While deaths from stroke and heart disease decreased between 1970 and 2002, death rates for COPD nearly doubled [1]. COPD is

\footnotetext{
* Correspondence: kschnel1@jhmi.edu

'Johns Hopkins University, 3400 North Charles Street, Baltimore, MD 21218, USA

Full list of author information is available at the end of the article
}

also a leading cause of hospitalizations in older adults [2], as well as of other morbidity.

COPD does not simply contribute to mortality. It may contribute substantially to difficulties with activities of daily living and disrupt social functioning [3]. A study in 2003, for example, found the presence of either moderate or severe COPD to be associated with a higher odds ratio of functional limitations [4].

The majority of patients with COPD have more than just COPD - comorbidities in COPD are the rule, rather than the exception. A study of 200 COPD patients from a managed care organization, for example, found that $94 \%$ of patients had at least one other chronic

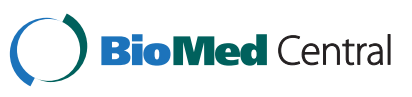


medical condition [5]. This is significant because comorbidities in COPD are associated with poorer outcomes, both for COPD and the other conditions [6,7]. Previous studies have shown an association between a variety of chronic conditions and COPD, including hypertension, diabetes, heart failure, coronary artery disease, and malignancy [6-9].

Previous studies on comorbidities in COPD have typically focused on selected chronic medical conditions, such as heart failure and diabetes. These studies have largely failed to look comprehensively at many other high-priority conditions, such as arthritis and obesity, and important functional limitations, like cognitive impairment and limited mobility. Functional limitations can have a significant impact on the treatment of chronic conditions, as patients may have difficulty adhering to treatment regimens [10]. These conditions may also modify the effectiveness of COPD therapy, cause potentially dangerous therapeutic interactions, and make COPD therapies less feasible.

Despite these potential interactions and the complexities of clinical decision-making for people with COPD, little population-based data on the prevalence of comorbidities in COPD is available. To date, there have been no nationally-representative studies of the prevalence of comorbidities in COPD. Moreover, COPD clinical practice guidelines do not provide specific recommendations for older patients with multiple comorbid diseases [11]. Thus, in this study, we aim to describe the prevalence of clinically-relevant comorbid conditions that add to the complexity of clinical decision-making or selfmanagement of COPD in a nationally-representative population of people with physician-diagnosed COPD. We also compare these prevalence estimates to those seen in subjects without COPD, to gain a better understanding of which conditions in particular are more common in people with COPD.

\section{Methods}

\section{Study population}

NHANES is a nationally-representative study designed to assess the health and nutritional status of noninstitutionalized civilians in the US. Collection of information occurs through home interviews and exams in mobile centers. Study details, including operations manuals, are publicly available [12]. To ensure adequate sample size in age and gender strata, we joined five survey waves (1999-2000, 2001-2002, 2003-2004, 20052006, and 2007-2008). This created an analytic sample of 14,828 people age 45 and older, including 995 with COPD. Using the sampling weights described below, this sample represents around 100 million people, 10 million of whom have COPD. From 1999-2008, the NHANES interview response rates ranged from $78 \%$ to
$84 \%$. Of those interviewed, $75 \%$ to $80 \%$ completed the physical exam.

\section{Definition of conditions}

COPD and comorbid disease status were ascertained largely through NHANES questions asking "has a doctor or other health professional ever told you that you have [disease]?" Physician-diagnosed COPD was defined as a positive response to either chronic bronchitis or emphysema with a negative response to current asthma. Subjects were defined as having a history of smoking if they reported having smoked $>100$ cigarettes total in their life.

Coronary heart disease (CHD) was defined by an affirmative response to at least one of $\mathrm{CHD}$, angina, or heart attack. For diabetes (DM), subjects were able to report prediabetes (2007-2008) or borderline diabetes (1999-2008). Among those reporting either prediabetes or borderline diabetes, individuals were counted as having DM if they took insulin or a pill for diabetes, suffered from retinopathy, and for 1999-2004, if they had a lower extremity ulcer that took more than 4 weeks to heal, or had numbness or tingling in their hands or feet due to diabetes.

Glomerular filtration rate (GFR) was calculated using the Modification of Diet in Renal Disease (MDRD) equation based on serum creatinine, age, race, and gender. Low GFR was defined as an estimated GFR $<60 \mathrm{~mm} / \mathrm{L}$ [13]. Low hemoglobin was defined as $<12 \mathrm{~g} / \mathrm{dL}$ in women and $<13 \mathrm{~g} / \mathrm{dL}$ in men [13]. Urinary incontinence was ascertained by self-report of leaking urine at least a few times a month. Polypharmacy was defined as selfreported regular use of $>4$ prescription medications, following a previously established cut point [13]. Prescription dietary supplements were not counted as medications. For 1999-2000, prescription analgesics used on a chronic basis were not included in the count. Prescription analgesics were included in the drug count from 2001-2008.

Hypertension (HTN) was defined as mean systolic blood pressure $\geq 140 \mathrm{mmHg}$ on exam, mean diastolic blood pressure $\geq 90 \mathrm{mmHg}$, and/or current use of an antihypertensive $[9,14]$. The mean blood pressures were calculated following NHANES protocol [12]. If there was more than one reading, the first reading was excluded from the mean; otherwise, the sole reading was considered the "mean." Hypercholesterolemia was similarly defined by a total serum cholesterol $>6.21 \mathrm{mmol} / \mathrm{L}$ or current use of a hyperlipidemia drug. Depression and anxiety were defined as self-reported current use of an antidepressant or anxiolytic, respectively.

Memory problems were defined as an affirmative response or "don't know" to the question "are you limited in any way because of difficulty remembering or because 
you experience periods of confusion?" Mobility difficulty was considered present if the individual reported difficulty walking 0.25 miles or up to 10 steps without equipment. Visual impairment was ascertained through selfreported extreme difficulty reading newsprint or seeing up close, or, an examined visual acuity score of $<20 / 50$ in the better eye. Hearing impairment was defined according to self-report of "a lot" of trouble hearing or use of a hearing aid.

Individuals who reported dizziness or imbalance lasting at least 2 weeks or for an unknown duration, or, difficulty with balance in the last year, were counted as having problems with dizziness or balance. This variable was only available from 1999-2004; we present the prevalence only for the population from 1999-2004. A history of cancer was defined by self-report of having been diagnosed with cancer, excluding non-melanoma and unknown skin cancers. Subjects were considered obese if their body mass index (BMI) was $\geq 30 \mathrm{~kg} / \mathrm{m}^{2}$.

Frailty was defined according to four of the five criteria developed in the Cardiovascular Health Study [15] and Women's Health and Aging Studies [16], modified for NHANES [17]. Subjects from survey years 19992006 were defined as "frail" if they had $\geq 3$ of the four following characteristics: low BMI, weakness, exhaustion, and low physical activity. Low BMI was defined as a BMI $\leq 18.5 \mathrm{~kg} / \mathrm{m}^{2}$. Weakness was defined as a response of "some difficulty," "much difficulty," or "unable to do" when asked how difficult they find it to lift 10 pounds. Exhaustion was defined using these same responses when asked how difficult they find it to walk from one room to another on the same level. Low physical activity was defined as reporting less activity than other people of the same age. Physical activity relative to others of the same age was not assessed in 2007-2008. Therefore, subjects from 2007-2008 were considered frail if they had a low BMI and reported both weakness and exhaustion.

\section{Condition groupings}

We grouped the conditions into three domains - diseases, clinical factors, and health status factors. As outlined in Boyd et al., the disease domain encompasses traditional chronic diseases that are considered of major importance because they are established as leading causes of death or morbidity [13]. The clinical domain consists of physiological conditions and factors that should be weighed when prescribing therapies (e.g., polypharmacy). The health status domain was reserved for conditions that affect function and quality of life, are likely to affect a person's ability to adhere to therapy, and are often caused by several processes in older adults [13].

\section{Analytic plan}

The National Center for Health Statistics (NCHS) provides sampling weights that account for sampling strategy and survey non-response. Using methods provided by NCHS, we modified the original weights in our combined sample to maintain national representation [18]. We performed analyses with statistical software designed to conduct subpopulation analyses using masked variance units to estimate appropriate standard errors. We summarize baseline characteristics using means and 95\% confidence intervals. Differences in these variables between subjects with and without COPD were compared using a $X^{2}$ test.

We ran the analysis stratified by age group. The analyses were rerun in the subset of COPD subjects with a history of smoking to test the sensitivity of the COPD definition. To address multiple testing, we reported both the STATA-generated $\mathrm{p}$-value and a Bonferronicorrected significance level $(\alpha)$ [19].

All analyses were carried out in STATA version 11.1. The study protocol was approved by the Johns Hopkins University School of Medicine Institutional Review Board.

\section{Results}

The prevalence of comorbid chronic disease among subjects with physician-diagnosed COPD was: congestive heart failure (12.1\%), coronary heart disease (12.7\%),hypertension (60.4\%), hypercholesterolemia (47.6\%), stroke (8.9\%), diabetes (16.3\%), osteoporosis (16.9\%), arthritis (54.6\%), cancer (16.5\%), depression (20.6\%), and anxiety (8.6\%). Clinical factors potentially complicating the treatment of COPD were: dizziness or balance problems (41.1\%), obesity $(40.3 \%)$, urinary incontinence $(34.9 \%)$, anemia (9.3\%), low GFR (16.2\%), use of $>4$ prescription medications (51.8\%), and frailty (9.5\%). Subjects with COPD were also found to have the following "health status" factors: memory problems (18.5\%), mobility difficulty (55.6\%), hearing impairment (12.1\%), and visual impairment (14.0\%). 96.4\% of subjects with COPD had at leastone comorbidity.

Table 1 describes the basic demographic features of those with and without COPD. Those with COPD tended to be older and female.

Figures 1, 2 and 3 depict the prevalence rates of conditions in the three domains (diseases, clinical factors, and health status factors) in subjects with COPD. These figures provide a visual illustration of the high prevalence of comorbidities in patients with physician-diagnosed COPD; they do not statistically compare groups. The majority of the conditions are markedly more common in the $\geq 65$ age group than in the younger age groups. While some conditions are more common in one gender than the other (depression, CHD, osteoporosis, and hearing 
Table 1 Demographics and smoking history: adults $\geq 45$ years, with and without physician-diagnosed COPD: NHANES 1999-2008

\begin{tabular}{|c|c|c|}
\hline \multirow[t]{2}{*}{ Demographic Variables } & \multirow{2}{*}{$\frac{\text { Without COPD }}{(n=14,828)^{a}}$} & \multirow{2}{*}{$\frac{\text { With COPD }}{(n=995)^{b}}$} \\
\hline & & \\
\hline Age, mean yr (95\% Cl) & $60.0(59.6-60.3)$ & $62.7(61.7-63.8)$ \\
\hline \multicolumn{3}{|l|}{ Gender } \\
\hline Male \% (95\% Cl) & $47.0(46.2-47.9)$ & $39.9(36.0-44.0)$ \\
\hline Female, \% (95\% Cl) & $53.0(52.1-53.8)$ & $60.1(56.0-64.0)$ \\
\hline \multicolumn{3}{|l|}{ Race } \\
\hline White, \% (95\% Cl) & $76.4(73.5-79.1)$ & $84.6(81.4-87.4)$ \\
\hline Black, \% (95\% Cl) & $10.0(8.5-11.8)$ & $6.8(5.1-8.9)$ \\
\hline Hispanic, \% (95\% Cl) & $8.8(7.0-11.0)$ & $4.4(3.0-6.3)$ \\
\hline
\end{tabular}

\section{Smoking History}

\begin{tabular}{lll}
\hline Ever smoker, \% $(95 \% \mathrm{Cl})$ & $52.1(50.7-53.4)$ & $68.9(65.2-72.5)$ \\
\hline
\end{tabular}

$>10$ pack years, $\%(95 \% \mathrm{Cl})$

$26.8(25.7-27.9)$

${ }^{a}$ Represents $\sim 100$ million noninstitutionalized US civilians.

${ }^{\mathrm{b}}$ Represents $\sim 10$ million noninstitutionalized US civilians.

impairment), others, such as polypharmacy, obesity, dizziness or balance problems, and memory problems are equally common among the two genders. Missing bars on the graph represent conditions for which the sample size was small in a given gender and age group.

Table 2 compares the prevalence rates of the conditions in subjects with COPD to those without COPD. Most of the conditions are significantly more prevalent in the subjects with COPD than in the subjects without COPD. While not shown in the table, some portion of these differences can be accounted for by differences in age and gender distribution in the COPD and nonCOPD groups. While not shown here, we found little difference in the prevalence of comorbid conditions between COPD subjects with and without a history of smoking,

Table 3 compares the prevalence of conditions in subjects with COPD to those prevalence values found in previous publications. The table also notes the country of study, the sample size, and the sampling method. We found that, in most cases, the population-based prevalence of comorbid conditions is at least as high, if not higher, as the prevalence found in these less-generalizable COPD populations.

\section{Discussion}

In this paper, we describe the prevalence of clinicallyrelevant comorbid conditions in a nationally-representative sample of people with physician-diagnosed COPD. We found that $96.4 \%$ of adults with physician-diagnosed COPD have at least one condition that may complicate the treatment of COPD. Most notably, 51.8\% of people with COPD 45 and older are taking more than 4 medications (polypharmacy), 55.6\% report mobility difficulty, $60.4 \%$ have hypertension, and $54.6 \%$ have arthritis.

These prevalence values are relatively consistent with those found in previous studies of comorbidities in COPD. However, there is a large range of previously reported prevalence values. For example, estimates of arthritis in COPD range from 22\% [5] to 70\% [23]. Neither of these studies, nor any other recent studies investigating comorbidity in COPD, have examined nationally-representative data. This both limits the applicability of these prevalence estimates and helps account for the large ranges in these estimates. In fact, several papers have cited lack of national representation or specific population bias as a weakness $[5,8,24]$. As such, our study both confirms the high prevalence of comorbidities in patients with

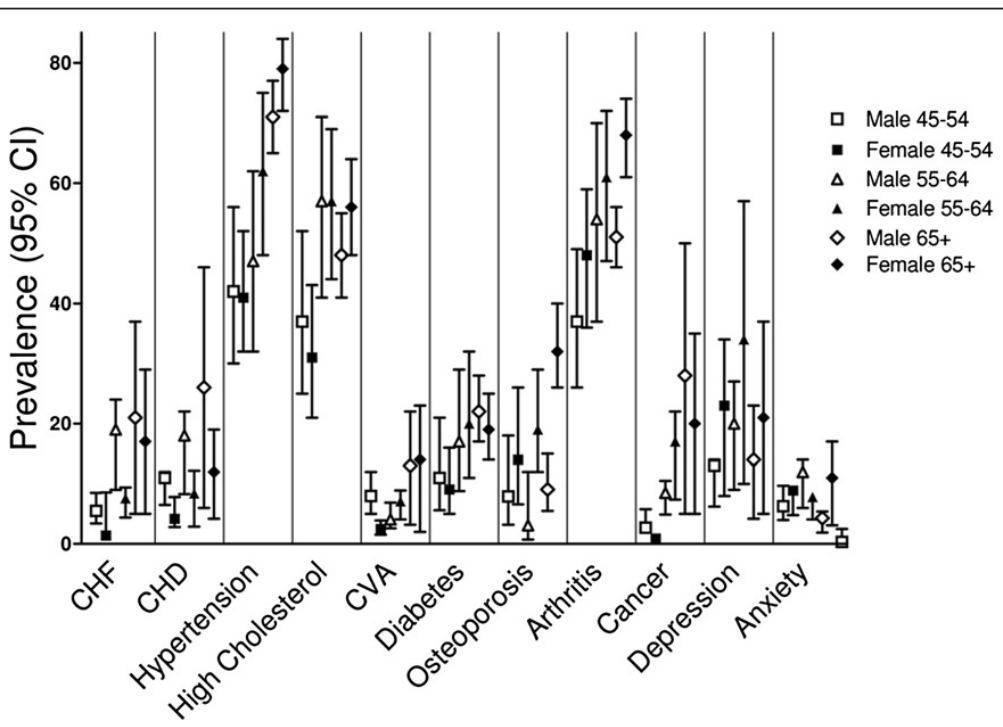

Figure 1 Prevalence of comorbidities stratified by age and gender among subjects with physician-diagnosed COPD: Disease Domain. 


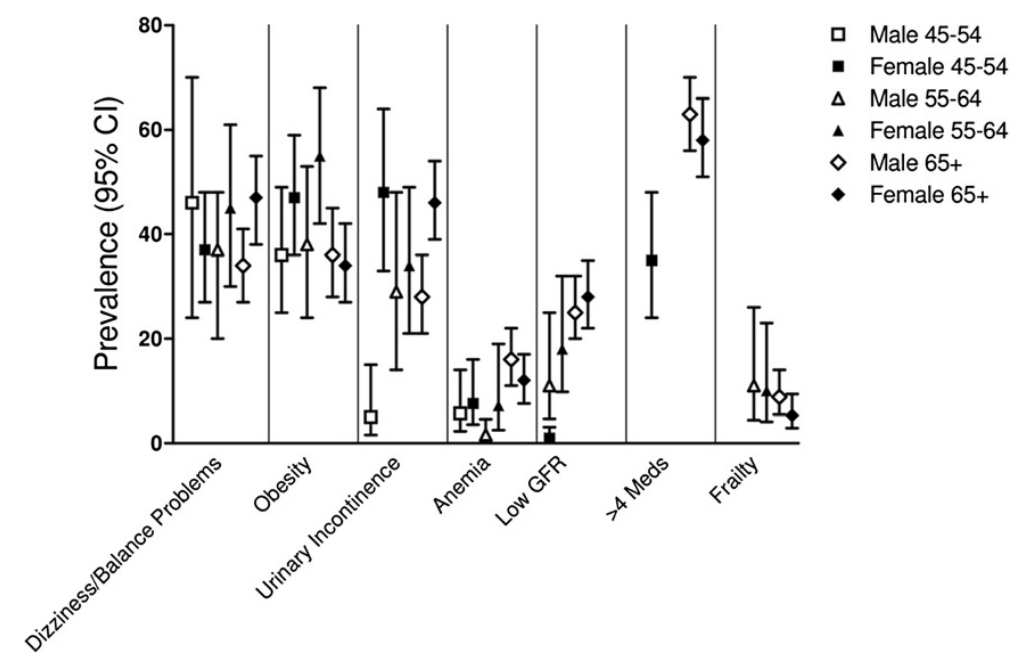

Figure 2 Prevalence of comorbidities stratified by age and gender among subjects with physician-diagnosed COPD: Clinical Factors.

COPD and provides specific prevalence values that are relevant on a national scale.

Another strength of our study is the range of clinically-relevant conditions assessed. While there is a lot of data on, for example, cardiovascular disease in COPD [8], there are few studies that look at the wide variety of medical conditions and functional limitations we have assessed. This is important partially because comorbidity has been found to be an important aspect of quality of life in COPD [25-27], as well as an independent risk factor for hospitalization [28]. In addition, comorbidities increase the risk of hospitalization and mortality in patients with COPD [8], and significantly increase the costs of treating COPD [29]. These conditions are also highly relevant for clinical decision-making and self-management.
The classification of the conditions into disease, clinical factor, and health status factor domains highlights that a wide range of conditions relevant to the clinical management of people with COPD are quite prevalent, and that these relevant conditions extend beyond traditionally-defined diseases.

Physicians must be judicious when caring for patients with COPD. The high prevalence of comorbidity and polypharmacy means physicians must be cognizant of potential adverse drug events and nonadherence. People with COPD are often complex, and, thus, we will need to improve our ability to prioritize treatment recommendations based on relative benefits and harms and patient preferences. Current guidelines, and our evidence base, do not yet adequately inform this critical clinical decision-making [13].

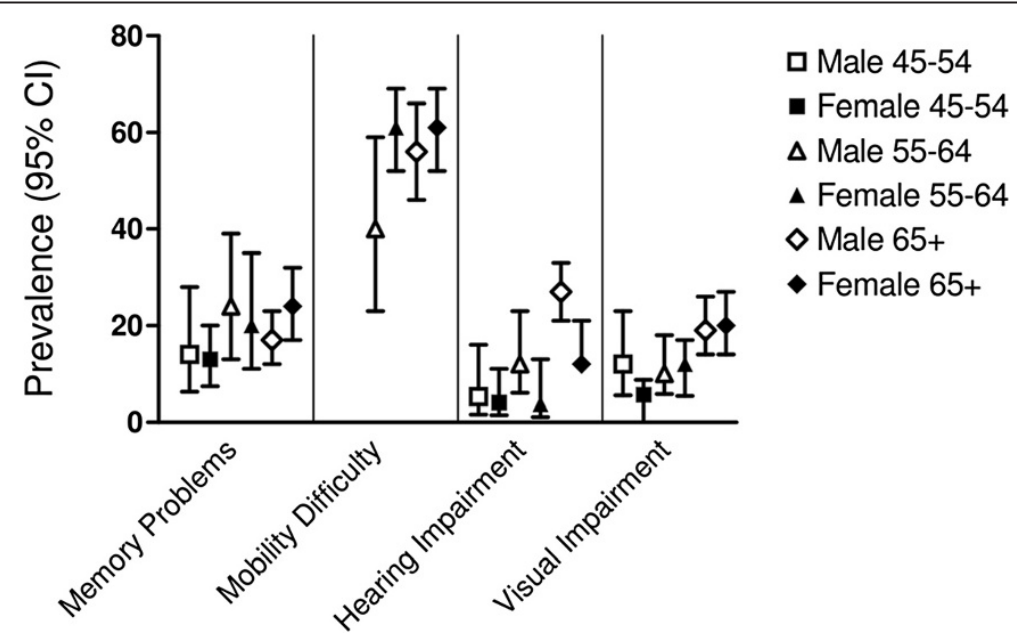

Figure 3 Prevalence of comorbidities stratified by age and gender among subjects with physician-diagnosed COPD: Health Status Factors. 
Table 2 Prevalence of comorbidities: adults $\geq 45$ with and without physician-diagnosed COPD: NHANES 1999-2008

\begin{tabular}{|c|c|c|c|}
\hline \multirow[t]{2}{*}{ Conditions } & \multirow{2}{*}{$\frac{\text { Without COPD }}{(n=14,828)^{a}}$} & \multirow{2}{*}{$\frac{\text { With COPD }}{(n=995)^{b}}$} & \multirow{2}{*}{$\begin{array}{l}\text { P- } \\
\text { value }\end{array}$} \\
\hline & & & \\
\hline \multicolumn{4}{|l|}{ Diseases } \\
\hline CHF, \%, (95\% Cl) & $3.9(3.6-4.3)$ & $12.1(9.8-14.8)$ & $<.0001$ \\
\hline $\mathrm{CHD}, \%,(95 \% \mathrm{Cl})$ & $6.1(5.5-6.7)$ & $12.7(10.5-15.3)$ & $<.0001$ \\
\hline HTN, \%, (95\% Cl) & $52.2(50.7-53.7)$ & $60.4(55.8-64.8)$ & 0.0006 \\
\hline High cholesterol, \%, (95\% Cl) & $41.3(39.9-42.6)$ & $47.6(43.0-52.2)$ & 0.0096 \\
\hline CVA, \%, (95\% Cl) & $4.6(4.2-5.0)$ & $8.9(7.0-11.1)$ & $<.0001$ \\
\hline Diabetes, \%, (95\% Cl) & $12.8(12.1-13.7)$ & $16.3(13.3-19.8)$ & 0.0184 \\
\hline Osteoporosis, \%, (95\% Cl) & $8.5(7.8-9.2)$ & $16.9(13.7-20.7)$ & $<.0001$ \\
\hline Arthritis, \%, (95\% Cl) & $36.9(35.6-38.2)$ & $54.6(49.8-59.3)$ & $<.0001$ \\
\hline Cancer, \%, (95\% Cl) & $9.9(9.3-10.6)$ & $16.5(14.2-19.0)$ & $<.0001$ \\
\hline Depression, \%, (95\% Cl) & $12.5(11.8-13.3)$ & $20.6(17.1-24.6)$ & $<.0001$ \\
\hline Anxiety, \%, (95\% Cl) & $3.8(3.3-4.3)$ & $8.6(6.6-11.1)$ & $<.0001$ \\
\hline \multicolumn{4}{|l|}{ Clinical Factors } \\
\hline Dizziness/Balance Problems, \%, $(95 \% \text { Cl) })^{d}$ & $23.8(22.4-25.4)$ & $41.1(36.3-46.1)$ & $<.0001$ \\
\hline Obesity, \%, (95\% Cl) & $33.5(32.0-35.1)$ & $40.3(36.4-44.4)$ & 0.0013 \\
\hline Urinary Incontinence, \%, (95\% Cl) & $27.3(26.1-28.7)$ & $34.9(29.6-40.5)$ & 0.0048 \\
\hline Anemia, \%, $(95 \% \mathrm{Cl})$ & $6.2(5.5-7.1)$ & $9.3(7.1-12.0)$ & 0.0030 \\
\hline Low GFR, \%, (95\% Cl) & $10.5(9.7-11.2)$ & $16.2(13.3-19.5)$ & $<.0001$ \\
\hline$>4$ meds, \%, $(95 \% \mathrm{Cl})$ & $32.1(30.5-33.8)$ & $51.8(46.2-57.2)$ & 0.0022 \\
\hline Frailty, \%, (95\% Cl) & $3.1(2.7-3.6)$ & $9.5(7.0-12.8)$ & $<.0001$ \\
\hline \multicolumn{4}{|l|}{ Health Status Factors } \\
\hline Memory problems, \%, (95\% Cl) & $8.8(8.1-9.5)$ & $18.5(14.9-22.7)$ & $<.0001$ \\
\hline Mobility difficulty, \%, (95\% Cl) & $32.5(30.7-34.4)$ & $55.6(50.6-60.5)$ & $<.0001$ \\
\hline Hearing impairment, \%, (95\% Cl) & $8.3(7.7-8.9)$ & $12.1(9.8-14.9)$ & 0.0008 \\
\hline Visual impairment, \%, (95\% Cl) & $9.6(9.0-10.3)$ & $14.0(12.0-16.2)$ & $<.0001$ \\
\hline \multicolumn{4}{|l|}{ All Conditions } \\
\hline$>=1$ comorbid condition, \%, (95\% Cl) & $87.7(86.4-88.8)$ & $96.4(94.3-97.8)$ & $<.0001$ \\
\hline
\end{tabular}

${ }^{a}$ Represents $\sim 100$ million noninstitutionalized US civilians.

${ }^{\mathrm{b}}$ Represents $\sim 10$ million noninstitutionalized US civilians.

c The Bonferroni-corrected significance level, a, is 0.0011 .

d Only assessed 1999-2004.

Clinical practice guidelines generally do not address how to treat COPD in the context of comorbid conditions [11]. As such, these guidelines may be of little help when dealing with the majority of COPD patients $[30,31]$. For example, $\beta$-blockers, which are indicated for cardiovascular disease, may worsen lung function in some patients with COPD; some studies, however, have shown that this is not a contraindication to the initiation of $\beta$-blockers [32]. Conversely, bronchodilators, which are believed to be beneficial for pulmonary function, may worsen tachyarrhythmias [9]. Guidance about these potential interactions, and the quality of evidence supporting any recommendations about them, would be very useful to clinicians. Our results can inform clinical practice guideline priority-setting processes to determine which comorbidities should be addressed in future COPD guidelines.
It is imperative that therapeutic trials be designed to reflect the true population of people with COPD. Many studies exclude patients with significant comorbid conditions [33]. Herland et al. found that only $17 \%$ of a group of COPD patients would be eligible for a "typical" clinical trial. $65.9 \%$ of COPD patients in this study were "excluded" due to significant comorbidities, including diabetes, depression, and ischemic heart disease [34]. These exclusions may be troublesome given the high prevalence of these diseases in people with COPD, and the potential for interactions between the diseases and their treatments. Our study highlights the need for future clinical trials to evaluate safety and effectiveness in COPD patients with multiple comorbidities.

There is evidence that treating COPD may benefit the course of comorbid conditions, and, visa-versa [35]. For example, several observational studies have shown 
Table 3 Comparison: the prevalence of comorbidities in subjects with COPD from previous studies

\begin{tabular}{|c|c|c|c|c|c|c|c|c|c|c|}
\hline \multirow[t]{2}{*}{ Source } & \multirow[t]{2}{*}{$\mathrm{n}$} & \multirow[t]{2}{*}{ Study location } & \multirow{2}{*}{$\begin{array}{l}\text { Age } \\
\text { range }\end{array}$} & \multirow{2}{*}{$\begin{array}{l}\text { Method of } \\
\text { comorbidity } \\
\text { ascertainment }\end{array}$} & \multirow{2}{*}{$\frac{\text { Arthritis }}{\text { (\%) }}$} & \multirow{2}{*}{$\frac{\mathrm{HTN}}{(\%)}$} & \multirow{2}{*}{$\frac{\text { Diabetes }}{(\%)}$} & \multirow{2}{*}{$\frac{\text { Depression }}{(\%)}$} & \multirow{2}{*}{$\frac{\text { Cancer }}{(\%)}$} & \multirow{2}{*}{ Osteoporosis } \\
\hline & & & & & & & & & & \\
\hline $\begin{array}{l}\text { van Manen } \\
\text { et al.[20] }\end{array}$ & 1145 & Netherlands & $40+$ & $\begin{array}{l}\text { Self-report via } \\
\text { written survey }\end{array}$ & 36 & 23 & 5 & 9 & 6 & - \\
\hline Mapel et al.[5] & 200 & New Mexico & $30+$ & Chart abstraction & 22 & 45 & 12 & 17 (w/other psych) & 18 & - \\
\hline Soriano et al. [21] & 2699 & United Kingdom & All ages & $\begin{array}{l}\text { Read codes } \\
\text { from GPRD* }\end{array}$ & 28 & - & - & 10 (w/other psych) & 4 & - \\
\hline Sidney et al. [22] & 45966 & $\begin{array}{l}\text { US, Kaiser Permanente } \\
\text { Members }\end{array}$ & $40+$ & $\begin{array}{l}\text { ICD9 discharge } \\
\text { codes }\end{array}$ & - & 18 & 2 & - & - & - \\
\hline $\begin{array}{l}\text { Walsh and } \\
\text { Thomashow [23] }\end{array}$ & 3000 & US & All ages & $\begin{array}{l}\text { Phone and } \\
\text { internet surveys }\end{array}$ & 70 & 52 & 16 & 35 & 4 & 32 \\
\hline Current Study & $995^{\dagger}$ & US & $45+$ & NHANES & 54 & 60 & 16 & 21 & 16 & 17 \\
\hline
\end{tabular}

improved outcomes in COPD patients treated with statins [36,37], independent of whether patients have a comorbid diagnosis of ischemic heart disease [38]. While a randomized controlled trial has shown an improvement in exercise tolerance in COPD patients treated with statins [39], more prospective intervention trials are needed to look at the use of statins in COPD [40].

Given these potential complications of treatment and the interactions between comorbid conditions and COPD, some researchers have started to advocate for an integrated-care approach to the management of patients with COPD. Sonetti et al. in a recent review advocate for a chronic care model approach to COPD management, with an approach that includes automatic screening for common comorbidities [41,42]. In order to truly move to such a system, however, it is necessary to have a good understanding of how best to treat COPD in the context of comorbid conditions. First steps to accomplishing this are (a) determining common "patterns" of co-existing conditions (b) including patients with comorbid conditions in clinical trials with appropriate analytic strategies to understand heterogeneity of treatment effect [43] (c) evaluating current treatment regimens in patients with different patterns of comorbid conditions and (d) continuing to study possible pathophysiologic connections between COPD and comorbidities. Further research should also continue to explore the effects comorbid conditions have on outcomes (health-related and other) in COPD.

\section{Limitations}

As spirometry data is not available in NHANES 19992006, we were not able to look at comorbidities in the context of the severity of COPD. This is significant because a recent study showed that increased respiratory impairment was associated with a higher risk of having comorbid hypertension, CVD, and diabetes [8].
Also due to the absence of spirometry data, we defined COPD via self-report. While this does not meet the gold standard definition for COPD (which is spirometric) [5], we are aware of no other applicable datasets that are nationally-representative and as comprehensive and current as NHANES 1999-2008. For example, NHANES 1988-1994 has spirometry data on a subset of participants; but, given the changing demographics of the US, it is unlikely this data is entirely representative of the current US population.

We acknowledge that the prevalence of comorbidities in physician-diagnosed COPD may be different than that in spirometrically-defined COPD; for example, patients with a higher burden of disease and lower health status may be more likely to receive a physician diagnosis of COPD. There is also likely misclassification of some subjects - subjects with spirometrically-defined COPD in the group without physician-diagnosed COPD, and subjects who reported a physician-diagnosis of COPD, but who would not meet spirometric criteria. Given the available data, and the desire to assess comorbidities in a larger sample of adults across multiple waves of NHANES, we believe physician-diagnosed COPD is a relevant outcome.

A study by Barr et al. found that self-report-based surveys are an appropriate way to study respiratory disease in healthcare professionals [44], and many studies of comorbidities in COPD have used self-report [20]. We found little difference in the prevalence of comorbid conditions between COPD subjects with and without a history of smoking, which helps validate our definition of COPD. Our definitions of many of the comorbidities were similarly limited by the need to, in some cases, define conditions by self-report.

We were also limited by factors included in the NHANES data set. We would have liked to assess warfarin use in COPD patients (our sample size was too 
small), human immunodeficiency virus (NHANES only runs HIV tests on subjects between the ages of 18 and 49), insomnia/sleeping problems [27] (only assessed in NHANES 2005-2008), gastroesophageal reflux disease, pulmonary embolism, and pneumonia (these conditions were not directly assessed in NHANES).

\section{Conclusions}

Comorbid conditions are the rule, not the exception, in patients with physician-diagnosed COPD. While $96.4 \%$ of adults 45 and older with COPD have at least one condition that may complicate the treatment of COPD, few trials or practice guidelines take these conditions into consideration. Describing the nationally-representative prevalence of comorbid conditions in patients with physician-diagnosed COPD is the first step towards developing an evidence base, and clinical practice guidelines, that better represent the true population of patients with COPD.

\section{Competing interests}

Dr. Bruce Leff has served on a strategic advisory board to Amedisys Inc and has consulted with Intersection LLC via a consulting agreement between Intersection LLC and Johns Hopkins Medicine. All other authors declare that they have no competing interests.

\section{Acknowledgments}

\section{Funders}

This work was funded in part by the Johns Hopkins Predoctoral Clinical Research Training Program grant number 1TL1RR-025007 from the National Center for Research Resources (NCRR), a component of the National Institutes of Health (NIH) Dr. Boyd was supported by the Johns Hopkins Bayview Center for Innovative Medicine, The Robert Wood Johnson Foundation Physician Faculty Scholars Program, and the Paul Beeson Career Development Award Program (NIA K23 AG032910, AFAR, The John A. Hartford Foundation, The Atlantic Philanthropies, The Starr Foundation and an anonymous donor). Dr. Weiss was supported by the Robert Wood Johnson Foundation Amos Medical Faculty Development Program. Dr. Wolff was supported by NIMH K01 MH082885-2. The funding bodies had no direct role in the study design; in the collection, analysis, and interpretation of data; in the writing of the manuscript; or in the decision to submit the manuscript for publication.

\section{Prior Presentations}

We presented an earlier version of the manuscript as a poster at the 2011 American Geriatrics Society Conference in Washington DC.

\section{Author details}

'Johns Hopkins University, 3400 North Charles Street, Baltimore, MD 21218, USA. ${ }^{2}$ Hines VA Hospital \& University of Illinois at Chicago, 5000 South 5th Ave, P.O. Box 5000, Hines, IL 60141, USA. ${ }^{3}$ University of Illinois Hospital \& Health Sciences System, Medical Center Administration Building, 914 South Wood Street, MC 973, Chicago, IL 60612, USA.

\section{Authors' contributions}

KS carried out the initial literature search, contributed to conception and design, completed the data analysis and interpretation of data, and drafted and edited the manuscript. COW provided many of the condition definitions, contributed to the statistical analysis and interpretation of data, and revised the manuscript critically for important intellectual content. TL and JAK provided initial conceptual guidance, contributed to the study design, and revised it critically for important intellectual content. BL and JLW helped with initial conceptual guidance, aided in condition definitions, and revised it critically for important intellectual content. CB helped guide the initial literature search, contributed to the conception and design, helped with the data analysis and interpretation of data, and contributed significantly to the drafting, organization, and conclusions of the manuscript. All authors read and approved the final manuscript.

Received: 29 September 2011 Accepted: 13 June 2012 Published: 13 June 2012

\section{References}

1. Jemal A, Ward E, Hao Y, Thun M: Trends in the leading causes of death in the United States, 1970-2002. JAMA 2005, 294(10):1255-1259.

2. Mannino DM: COPD: epidemiology, prevalence, morbidity and mortality, and disease heterogeneity. Chest 2002, 121(5 Suppl):121S-126S.

3. Anecchino C, Rossi E, Fanizza C, De Rosa M, Tognoni G, Romero M, working group ARNO project: Prevalence of chronic obstructive pulmonary disease and pattern of comorbidities in a general population. Int J Chron Obstruct Pulmon Dis 2007, 2(4):567-574.

4. Mannino DM, Ford ES, Redd SC: Obstructive and restrictive lung disease and functional limitation: data from the Third National Health and Nutrition Examination. J Intern Med 2003, 254(6):540-547.

5. Mapel DW, Hurley JS, Frost FJ, Petersen HV, Picchi MA, Coultas DB: Health care utilization in chronic obstructive pulmonary disease. A case-control study in a health maintenance organization. Arch Intern Med 2000, 160 (17):2653-2658.

6. Holguin F, Folch E, Redd SC, Mannino DM: Comorbidity and mortality in COPD-related hospitalizations in the United States, 1979 to 2001. Chest 2005, 128(4):2005-2011.

7. Patil SP, Krishnan JA, Lechtzin N, Diette GB: In-hospital mortality following acute exacerbations of chronic obstructive pulmonary disease. Arch Intern Med 2003, 163(10):1180-1186.

8. Mannino DM, Thorn D, Swensen A, Holguin F: Prevalence and outcomes of diabetes, hypertension and cardiovascular disease in COPD. Eur Respir J 2008, 32(4):962-969.

9. Chatila WM, Thomashow BM, Minai OA, Criner GJ, Make BJ: Comorbidities in chronic obstructive pulmonary disease. Proc Am Thorac Soc 2008, 5 (4):549-555.

10. Gray SL, Mahoney JE, Blough DK: Medication adherence in elderly patients receiving home health services following hospital discharge. Ann Pharmacother 2001, 35(5):539-545.

11. Boyd CM, Darer J, Boult C, Fried LP, Boult L, Wu AW: Clinical practice guidelines and quality of care for older patients with multiple comorbid diseases: implications for pay for performance. JAMA 2005, 294(6):716-724.

12. Centers for Disease Control and Prevention (CDC): National Center for Health Statistics (NCHS):: National Health and Nutrition Examination Survey. In Edited by. Hyattsville, MD: U.S. Department of Health and Human Services, Centers for Disease Control and Prevention; :1999-2008.

13. Boyd CM, Leff B, Wolff J, Yu Q, Zhou J, Rand C, Weiss C: Informing Clinical Practice Guideline Development and Implementation: Prevalence of Coexisting Conditions Among Adults with Heart Disease. Journal of the American Geriatrics Society 2011, 59:797-805.

14. Cerner Multum Inc: Multum Lexicon Drug Database.,

15. Fried LP, Tangen CM, Walston J, Newman AB, Hirsch C, Gottdiener J, Seeman T, Tracy R, Kop WJ, Burke G, McBurnie MA: Cardiovascular Health Study Collaborative Research Group: Frailty in older adults: evidence for a phenotype. J Gerontol A Biol Sci Med Sci 2001, 56(3):M146-M156.

16. Bandeen-Roche K, Xue QL, Ferrucci L, Walston J, Guralnik JM, Chaves P, Zeger SL, Fried LP: Phenotype of frailty: characterization in the women's health and aging studies. J Gerontol A Biol Sci Med Sci 2006, 61(3):262-266.

17. Wilhelm-Leen ER, Hall YN, Tamura MK, Chertow GM: Frailty and chronic kidney disease: the Third National Health and Nutrition Evaluation Survey. Am J Med 2009, 122(7):664-671. e2.

18. Centers for Disease Control and Prevention (CDC): National Center for Health Statistics (NCHS).: National Health and Nutrition Examination Survey Analytic and Reporting Guidelines. In Edited by. Hyattsville, MD: U.S. Department of Health and Human Services, Centers for Disease Control and Prevention; 2006.

19. Dunn OJ: Multiple Comparisons Among Means. Journal of the American Statistical Association 1961, 56:52-64.

20. van Manen JG, Bindels PJ, IJzermans CJ, van der Zee JS, Bottema BJ, Schade E: Prevalence of comorbidity in patients with a chronic airway 
obstruction and controls over the age of 40. J Clin Epidemiol 2001, 54 (3):287-293.

21. Soriano JB, Visick GT, Muellerova H, Payvandi N, Hansell AL: Patterns of comorbidities in newly diagnosed COPD and asthma in primary care. Chest 2005, 128(4):2099-2107.

22. Sidney S, Sorel M, Quesenberry CP Jr, DeLuise C, Lanes S, Eisner MD: COPD and incident cardiovascular disease hospitalizations and mortality: Kaiser Permanente Medical Care Program. Chest 2005, 128(4):2068-2075.

23. Walsh JW, Thomashow BM: COPD and co-morbidities: results of COPD Foundation national survey, Paper presented at: COPD and co-morbidities: treating the whole patient. San Diego, CA: ATS 2006 San Diego International Conference; 2006:19-24.

24. Barr RG, Celli BR, Mannino DM, Petty T, Rennard SI, Sciurba FC, Stoller JK, Thomashow BM, Turino GM: Comorbidities, patient knowledge, and disease management in a national sample of patients with COPD. Am J Med 2009, 122(4):348-355.

25. Yeo J, Karimova G, Bansal S: Co-morbidity in older patients with COPD-its impact on health service utilisation and quality of life, a community study. Age Ageing 2006, 35(1):33-37.

26. Ferrer M, Alonso J, Morera J, Marrades RM, Khalaf A, Aguar MC, Plaza V, Prieto L, Anto JM: Chronic obstructive pulmonary disease stage and health-related quality of life. The Quality of Life of Chronic Obstructive Pulmonary Disease Study Group. Ann Intern Med 1997, 127(12):1072-1079.

27. van Manen JG, Bindels PJ, Dekker EW, ljzermans CJ, Bottema BJ, van der Zee JS, Schade E: Added value of co-morbidity in predicting health-related quality of life in COPD patients. Respir Med 2001, 95(6):496-504.

28. Oostenbrink JB, Rutten-van Molken MP: Resource use and risk factors in high-cost exacerbations of COPD. Respir Med 2004, 98(9):883-891.

29. Foster TS, Miller JD, Marton JP, Caloyeras JP, Russell MW, Menzin J: Assessment of the economic burden of COPD in the U.S.: a review and synthesis of the literature. COPD 2006, 3(4):211-218.

30. Sin DD, Anthonisen NR, Soriano JB, Agusti AG: Mortality in COPD: Role of comorbidities. Eur Respir J 2006, 28(6):1245-1257.

31. Frogale K, Schnell KM, Boyd CM: COPD, Comorbidity, and Disease-Specific Clinical Practice Guidelines, In: Chronic Obstructive Pulmonary Disease: Comorbidities and Systemic Consequences. New York: Humana Press: Edited by Nici L, ZuWallack R; 2012:193-210.

32. Anonymous: Can beta-blockers be used for people with COPD? Drug Ther Bull 2011, 49(1):2-5.

33. Halpin DM: Lessons from the major studies in COPD: problems and pitfalls in translating research evidence into practice. Prim Care Respir J 2010, 19(2):170-179.

34. Herland K, Akselsen JP, Skjonsberg OH, Bjermer L: How representative are clinical study patients with asthma or COPD for a larger "real life" population of patients with obstructive lung disease? Respir Med 2005, 99 (1):11-19.

35. Barnes PJ: Future treatments for chronic obstructive pulmonary disease and its comorbidities. Proc Am Thorac Soc 2008, 5(8):857-864.

36. Keddissi JI, Younis WG, Chbeir EA, Daher NN, Dernaika TA, Kinasewitz GT: The use of statins and lung function in current and former smokers. Chest 2007, 132(6):1764-1771.

37. Mancini GB, Etminan M, Zhang B, Levesque LE, FitzGerald JM, Brophy JM: Reduction of morbidity and mortality by statins, angiotensin-converting enzyme inhibitors, and angiotensin receptor blockers in patients with chronic obstructive pulmonary disease. J Am Coll Cardiol 2006, 47 (12):2554-2560.

38. Soyseth V, Brekke PH, Smith P, Omland T: Statin use is associated with reduced mortality in COPD. Eur Respir J 2007, 29(2):279-283.

39. Lee TM, Lin MS, Chang NC: Usefulness of C-reactive protein and interleukin- 6 as predictors of outcomes in patients with chronic obstructive pulmonary disease receiving pravastatin. Am J Cardiol 2008, 101(4):530-535.

40. Janda S, Park K, FitzGerald JM, Etminan M, Swiston J: Statins in COPD: a systematic review. Chest 2009, 136(3):734-743.

41. Sonetti DA, Hospenthal AC, Adams SG: Integrated management strategies for chronic obstructive pulmonary disease. J Multidiscip Healthc 2010, 3:181-188

42. Jassem E, Kozielski J, Gorecka D, Krakowiak P, Krajnik M, Slominski JM: Integrated care for patients with advanced chronic obstructive pulmonary disease: a new approach to organization. Pol Arch Med Wewn 2010, 120(10):423-428.
43. Kent DM, Kitsios G: Against pragmatism: on efficacy, effectiveness and the real world. Trials 2009, 10:48.

44. Barr RG, Herbstman J, Speizer FE, Camargo CA Jr: Validation of selfreported chronic obstructive pulmonary disease in a cohort study of nurses. Am J Epidemiol 2002, 155(10):965-971.

doi:10.1186/1471-2466-12-26

Cite this article as: Schnell et al:: The prevalence of clinically-relevant comorbid conditions in patients with physician-diagnosed COPD: a cross-sectional study using data from NHANES 1999-2008. BMC

Pulmonary Medicine 2012 12:26.

\section{Submit your next manuscript to BioMed Central and take full advantage of:}

- Convenient online submission

- Thorough peer review

- No space constraints or color figure charges

- Immediate publication on acceptance

- Inclusion in PubMed, CAS, Scopus and Google Scholar

- Research which is freely available for redistribution

Submit your manuscript at www.biomedcentral.com/submit
C Biomed Central 